\title{
Research on exhaust emission characteristics and technical route under CLTC cycle
}

\author{
Peilin Geng*, Yimin Wang, Wei Zhao, and Xionghui Zou \\ China Automotive Technology and Research Center Co., Ltd., Tianjin 300300, China
}

\begin{abstract}
Keywords: light duty, test cycle, light duty, emission, technology route.

Abstract. In this paper, the light duty that meets the China 6 emission standard is selected to study the emission characteristics of different emission control technology routes under China light-duty vehicle test cycle (CLTC). The results show that the cold start stage of CLTC cycle is still the stage with the most pollutant emissions. The THC, CO and NOx emissions of vehicles on the supercharged direct injection technology are higher than those on the naturally aspirated port fuel injection technology. In terms of reducing the exhaust emission, PHEV technology route is the best, followed by naturally aspirated PFI technology route, and then turbocharged direct injection with GPF route.
\end{abstract}

\section{Introduction}

Limits and measurement methods for emission from light duty vehicles (CHINA 6) has already been released in December 23, 2016, and implemented in some parts of the country in July 1, 2019. Compared with the previous emission standards, china 6 standard is basically separated from the European system, at the same level with the European and American standards, and even some places have surpassed the European and American standards, and are in the no man's land of innovation and development.

Test cycle is a benchmark working condition for detecting vehicle exhaust emissions. It has a direct impact on research and development, test and certification of vehicle. whether the test cycle can reflect the actual operation of the vehicle directly affects the development direction of vehicle emission control technology. WLTC (World Light Vehicle Test Cycle) from European standard is adopted in the test cycle of China 6. Compared with the previous NEDC cycle, WLTC cycle changes more frequently, which can reflect the actual driving situation of the vehicle, but there are still many differences between WLTC cycle and China's actual driving conditions, especially the idle ratio and average speed. Therefor WLTC can't really reflect the actual driving situation of Chinese vehicles. In order to solve this problem, China Light Vehicle test cycle (CLTC) came into being, which was issued in National standard Announcement No. 13 of 2019 and made up for the lack of its own test

\footnotetext{
* Corresponding author: gengpeilin@catarc.ac.cn
} 
cycle in China for a long time[1]. CLTC provides more options for measuring emissions and fuel consumption that is consistent with China's actual driving conditions.

In order to meet the strict requirements of the China 6 emission standard for light vehicles, Various emission control technologies are used in light duty, such as supercharging + direct injection, supercharging + direct injection + GPF, natural aspiration + Port Fuel Injection and hybrid technology. Many researches show that the direct injection engine has many advantages in power, economy and emission compared with the naturally aspirated PFI engines.However, there are also many problems in the direct injection engine, such as high $\mathrm{HC}$ and $\mathrm{CO}$ emissions, difficult to control NOx pollutants and more PN emissions[2-3]. Wu et al.[4] summarized the technology routes to deal with pollutant emission control according to the causes of pollutants such as CO, HC, NOx and PM/PN. However, it doesn't also put forward a suitable technical route of vehicle emission control from the technical route of vehicle emission control. At present, CLTC cycle has been applied to all heavy-duty commercial vehicles and new energy vehicles, and will be gradually introduced into emission, noise or other fields. However, there are few reports on the adaptability of CLTC cycle in light duty in China. Therefore, this paper has carried out the research on the emission characteristics and technical route of light vehicles based on CLTC to provide technical support for Importing CLTC to the light vehicle emission field.

\section{Experimental setup and method}

\subsection{Test cycle}

In this test, CLTC test cycle is selected to test the China 6 light vehicles, and CLTC test cycle is shown in Figure 1

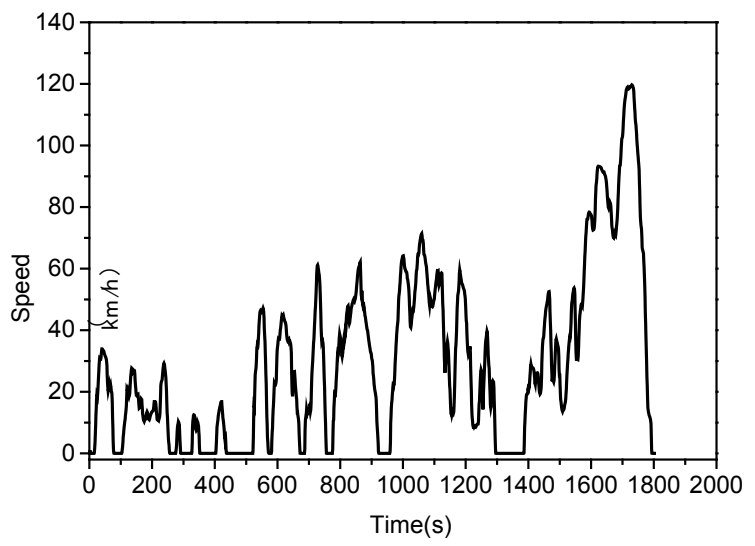

Fig. 1. CLTC test cycle curve.

As shown in Fig.1, CLTC is transient and variable conditions, which is composed of different speed segments, representing the operation of vehicles at low speed, medium speed and high speed. The driving time of CLTC cycle is $1800 \mathrm{~s}$, and the maximum speed and average speed are $114 \mathrm{~km} / \mathrm{h}$ and $29 \mathrm{~km} / \mathrm{h}$ respectively, and the maximum acceleration is $1.47 \mathrm{~m} / \mathrm{s}^{2}$. Compared with the WLTC and NEDC cycles, the maximum mileage and acceleration of CLTC are in the middle, and the highest speed and average speed are the smallest.The specific parameters are shown in table 1.

Table 1. Main parameters of NEDC, WLTC and CLTC test cycles.

\begin{tabular}{l|l|l|l|l|l|l} 
Test & Running & Mileage $(\mathrm{km})$ & Maximum & Average & Idle & Maximum
\end{tabular}




\begin{tabular}{|c|c|c|c|c|c|c|}
\hline cycle & time $(\mathrm{s})$ & & speed $(\mathrm{km} / \mathrm{h})$ & speed $(\mathrm{km} / \mathrm{h})$ & time $(\%)$ & acceleration(m/s2) \\
\hline WLTC & 1800 & 23.27 & 131.3 & 46.5 & 13.2 & 1.67 \\
\hline CLTC & 1800 & 14.48 & 114 & 29 & 22.1 & 1.47 \\
\hline NEDC & 1180 & 11.03 & 120 & 33.6 & 24.8 & 1.04 \\
\hline
\end{tabular}

\subsection{Test vehicle}

In the experiment, Four light-duty vehicles were selected, including three gasoline and one PHEV, and the engine displacement of traditional gasoline vehicles is $1.5 \mathrm{~L}$. Four vehicles represent four kinds of emission control technology routes: turbocharged direct injection GPF, turbocharged direct injection without GPF, Natural aspiration PFI without GPF and PHEV. The specific parameters of the test vehicles are shown in table 2.

Table 2. Parameters of test vehicles[1,5-6].

\begin{tabular}{ccccc}
\hline Parameter & Vehicle 1 & Vehicle 2 & Vehicle 3 & Vehicle 4 \\
\hline Engine type & Gasoline & Gasoline & Gasoline & PHEV \\
Displacement/L & 1.5 & 1.5 & 1.5 & 2.0 \\
Intake type & Supercharge & Supercharge & Natural & aspiration \\
Injection type & GDI & GDI & GDI & aspiration \\
$\begin{array}{c}\text { Gasoline particulate } \\
\text { filter }\end{array}$ & Yes & No & Yes & No \\
\hline
\end{tabular}

\subsection{Experimental method}

Full-flow dilution Constant Volume System(CVS), Horiba tail gas analyzer and particle count analyzer are used in the test. The connection and sampling position of the test equipment are shown in Figure 2

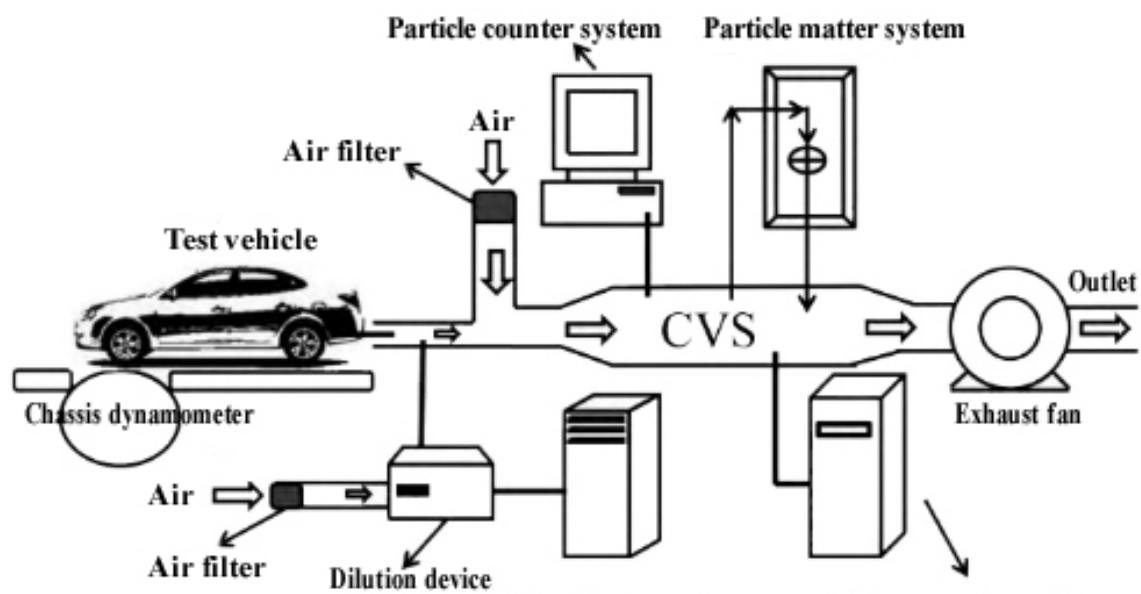

Particle size analyzer Exhaust emission analyzer

Fig. 2. The schematic diagram of experimental test bench.

HORIBA gas analyzer is used to analyze THC, CO, NMHC, NOx, and particle counter (PNC) was used to measure the particle number, and the fuel consumption is obtained by 
reversing the carbon emission from the exhaust gas. The specific parameters of the equipment are shown in table 3.

Table 3. Parameters of the equipment.

\begin{tabular}{cc}
\hline Device & specification \\
\hline Chassis dynamometer & AVL ROADSIM 48 \\
Sampling system & CVS-7400T \\
Exhaust analysis system & MEXA-7200H \\
Particle count analyzer & MEXA-2000SPCS \\
\hline
\end{tabular}

In the experiment, all the four vehicles run CLTC cycle under the same loading mode and environmental conditions. The pollutant emissions were measured by exhaust gas measuring equipment. Finally, according to the deterioration correction value (Table 4) given in China 6B of light vehicle, the emission of each pollutant is calculated by adding.

Table 4. Deterioration factor(DF).

\begin{tabular}{cccccc}
\hline \multirow{2}{*}{ Engine } & \multicolumn{5}{c}{$\mathbf{D F} /(\mathbf{m g} / \mathbf{k m})$} \\
\cline { 3 - 6 } & & $\mathrm{CO}$ & THC & NOx & PN \\
spark ignition type & $6 \mathrm{~b}$ & 110 & 16 & 15 & 0 \\
\hline
\end{tabular}

\section{Results and discussion}

\subsection{Transient pollutant emission}

In order to analyze the influence of the CLTC cycle on the transient pollutant emission, a turbocharged direct injection vehicle (vehicle 3) with GPF was selected. The experiment is carried out in the loading mode of china 6 . results are shown in fig. 2.

As can be seen from fig.2, the emissions of CO, THC, NOx and PN increased sharply within 100s of cold start whose proportion of the total pollutants is larger. During the follow-up test, $\mathrm{CO}$ and THC emissions are in a stable and low emission state. NOx is only a small amount in the acceleration stage, which is basically zero at other times. PN emissions are highly correlated with vehicle acceleration.

The analysis of the proportion of exhaust emissions within 100s of cold start shows that the $\mathrm{CO}$ emissions account for $65.2 \%$ of the total amount, and the THC emissions account for $23.9 \%$, and the NOx emissions account for $53.6 \%$, and the PN emissions account for $19.8 \%$. It can be seen that in the cold start phase which only accounts for $5.5 \%$ of the whole test cycle, the $\mathrm{CO}$ and NOx emissions contribute more than $50 \%$, and the THC and PN emissions contribute about $20 \%$. This is because in the cold start stage, the temperature of the three way catalyst is relatively low, so the operating temperature of the three way catalyst has not yet reached. The catalyst efficiency at this stage is relatively low, and the emissions of pollutants $\mathrm{CO}, \mathrm{THC}, \mathrm{NOx}$ and $\mathrm{PN}$ in the tail gas are relatively large. 


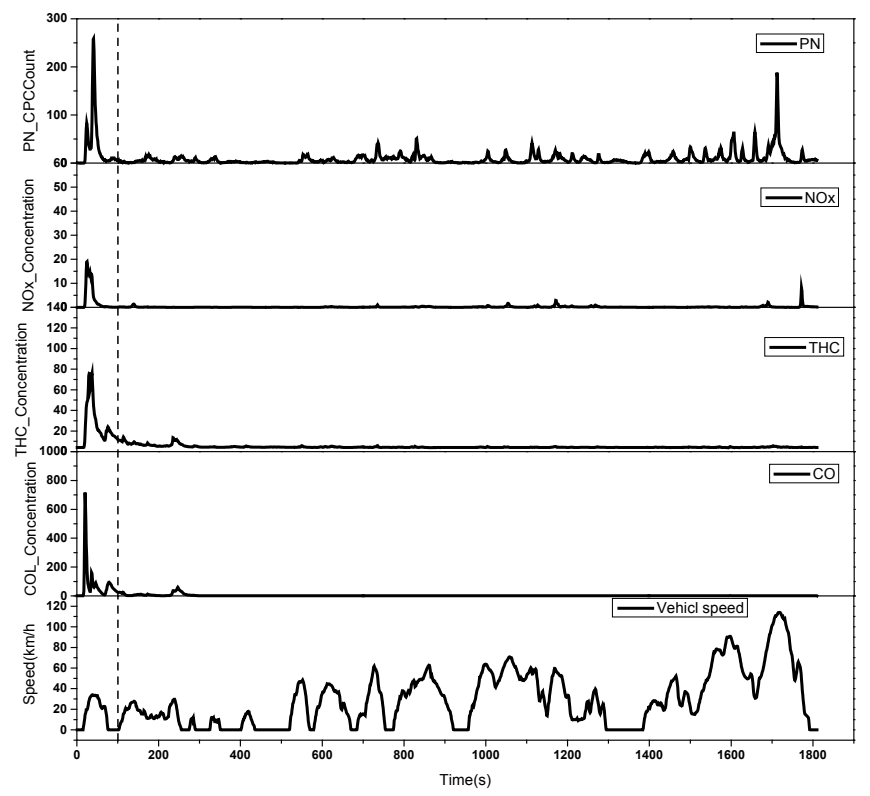

Fig. 3. Instantaneous pollutants emission under CLTC.

\subsection{The analysis on Emission technology route}

In order to study the emission characteristics of different emission control technology routes under CLTC cycle, this paper selects four mainstream emission control technology routes of the current market, corresponding to Vehicle 1, Vehicle 2, Vehicle 3 and Vehicle 4 in Table 2.

Fig. 4 presents the THC emission characteristics from four kinds of technology routes. From Fig. 4, it is found that the THC emission is within limits of China $6 \mathrm{~b}$ among the four technical routes. The THC emissions of turbocharged direct injection vehicles are larger than those of naturally aspirated PFI vehicles, and the THC emission of PHEV vehicles is the least. This is because compared with the PFI engine, it is difficult for GDI vehicles to achieve good stratified fuel consumption and homogeneous combustion at the same time, while insufficient combustion will generate a large number of THC. Compared with traditional vehicles, PHEV vehicles have shorter engine working time under the test cycle, which results in the reduction of $\mathrm{HC}$ emissions. It is also found that the $\mathrm{THC}$ emission of the turbocharged direct injection vehicle with GPF is very close to the limit, indicating that vehicles used this technical route still need to further optimize THC emissions. 


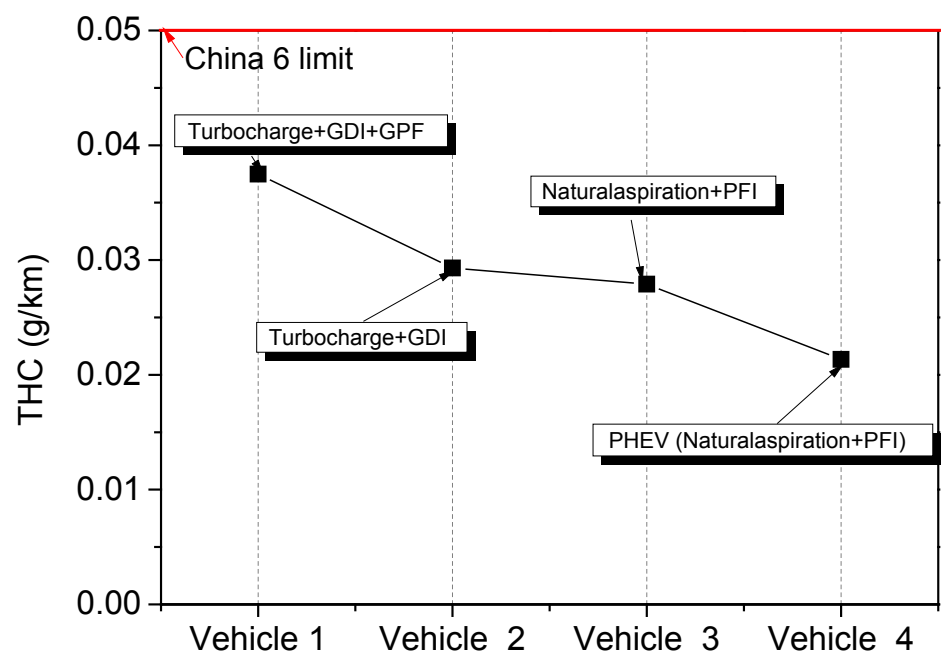

Fig. 4. THC emissions under different technology routes.

Fig. 5 presents the $\mathrm{CO}$ emission characteristics from four kinds of technology routes. From Fig. 5, it is found that the co emission is also within limits of China $6 \mathrm{~b}$ among the four technical routes. The CO emission of vehicles 1,2 and 3 is about $60 \%$ of the China $6 \mathrm{~b}$ limit, and the difference is little. The CO emission of PHEV vehicles is only $33.6 \%$ of the China $6 \mathrm{~b}$ limit, which is far lower than the limit value.

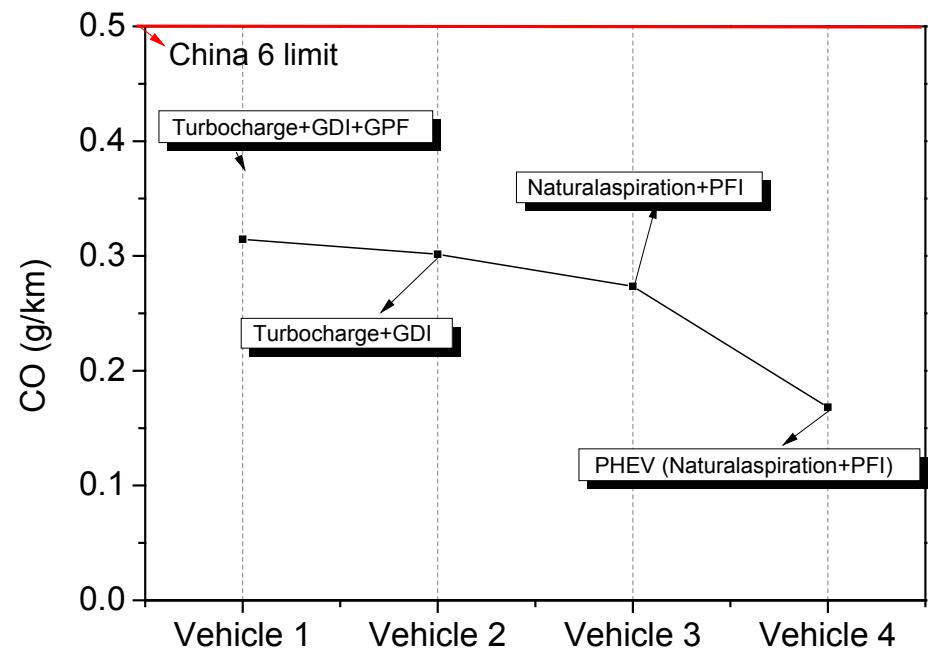

Fig. 5. CO emissions under different technology routes.

Fig. 5 presents the NOx emission characteristics from four kinds of technology routes. From Fig. 5, it is found that the NOx emission is also within limits of China $6 \mathrm{~b}$ among the four technical routes. The NOx emissions of turbocharged direct injection with GPF and turbocharged direct injection without GPF are similar, and higher than the NOx emissions of the other two technical routes, and the NOx emissions of PHEV technical routes are the least. This is because high temperature and rich oxygen are the factors that produce NOx. Compared with the homogeneous equivalent combustion of PFI engine, GDI engine adopts the thin stratified combustion technology. Because the mixture of GDI is stratified from 
rich to lean, there will inevitably be a partial concentration area near the air fuel ratio of 1 , which makes the combustion temperature of these areas high, so NOx emissions increase.At the same time, the higher compression ratio and the faster reaction heat release rate are also one of the reasons for the increase of NOx emission[7]. Compared with turbocharged direct injection vehicles with GPF, the NOx emission of naturally aspirated PFI vehicles with GPF is reduced by $10.5 \%$, and the NOx emission of PHEV vehicles is reduced by $25.7 \%$.

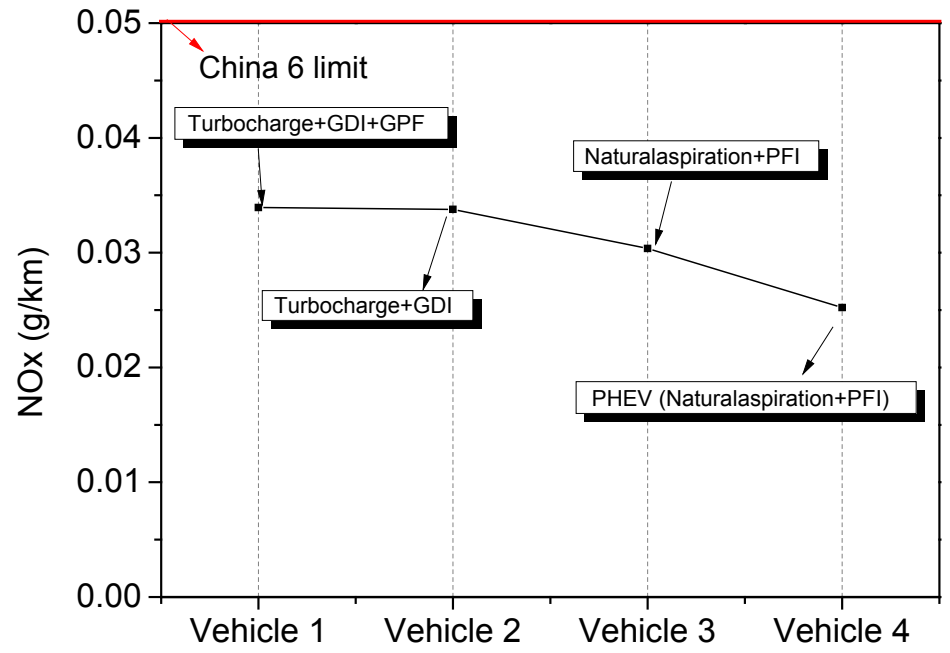

Fig. 5. NOx emissions under different technology routes.

Fig. 6 presents the PN emission characteristics from four kinds of technology routes. From Fig. 6, it is found that the PN emission is also within limits of China $6 \mathrm{~b}$ among the four technical routes. The PN emission of turbocharged direct injection without GPF is the largest, which is very close to the China $6 \mathrm{~b}$ limit. The PN emissions of turbocharged direct injection with GPF and naturally aspirated PFI vehicles without GPF have little difference, whose PN emission is only $50 \%$ of turbocharged direct injection without GPF. The PN emissions of PHEV vehicles are the least, only $11.5 \%$ of the PN emissions of turbocharged direct injection without GPF. It further illustrates the necessity of the turbocharged direct injection to cooperate with GPF. At the same time, it also shows that PHEV vehicles have a high advantage in reducing PN emissions. 


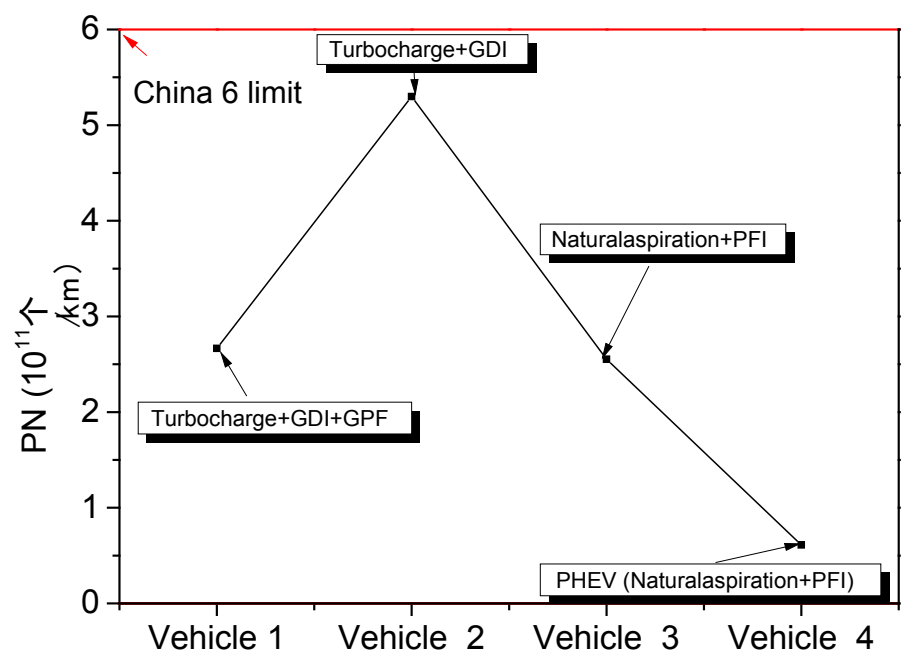

Fig. 6. $\mathrm{PN}$ emissions under different technology routes.

In a word, PHEV technology is the best way to reduce the emission of main exhaust emissions, followed by naturally aspirated PFI technology, and then turbocharged direct injection with GPF technology.

\section{Conclusion}

Based on study on Exhaust Emission Characteristics and technical route of China 6 light duty based on CLTC,it can be concluded as follows:

1) Cold start is still the stage with the most pollutant emission under CLTC cycle.

2) The THC, CO and NOx emissions of vehicles with turbocharged direct injection technology route are higher than those of naturally aspirated PFI.

3) The PN emission from turbocharged direct injection technology is high, and the PN emission level can be effectively reduced by coupling GPF.

4) In terms of reducing the exhaust emission, PHEV technology route is the best, followed by naturally aspirated PFI technology route, and then turbocharged direct injection with GPF route.

This work was financially supported by the Construction of Public Service Platform for Vehicle Emission/Energy Consumption Information System(Improvement of public service capacity of Industrial Technology Foundation 2018), the Integrated Technology of Particulate Matter Capture and Clean Emission for Gasoline Vehicles Projects (No.: 2017YFC0211004 and 2017YFC0211005).

\section{References}

1. China automotive test cycle Part 1: Light-duty vehicles (GB/T 38146.1-2019).

2. Zhang Pengyu, Zhang Xinyu, He Lijun, et al. Gasoline Direct Injection Technology[J]. Science \& Technology Information, 2012.

3. Yao Chunde,Wei Hongyuan, Geng Peilin,et al.Effect of MMT gasoline additive on PM emissions from a GDI and PFI gasoline engine[J]. Acta Scientiae Circumstantiae,2015(09):115-121. 
4. Wu Chunling, Cui Yingquan, Zhao Liang, et al. Technical path for light duty gasoline vehicle to meet China VI emission regualtion[J]. Automobile applied technology 2017(12):103-104.

5. Zhang Pengyu, Zhang Xinyu, He Lijun, et al. Analysis of Pollutant Emission Characteristics for Light-duty Vehicles under Different Test Cycles[J]. Vehicle \& Power Technology, 2016.

6. Guo Qianli, Zhao Donchang, Chen Pin,et al. Comparison of WLTC \& NEDC and Preliminary Study of Their Impact on Automobile Fuel Consumption [J]. Chinese Journal of Automotive Engineering,2017(3):44-52.

7. Lu Zhanhua. GDI Engine and the Optimum Technique of Lean Mixture Combustion[J]. Diesel Engine, 2003. 